\title{
ARTIGO
}

\section{ENDIVIDAMENTO EM OPERADORAS DE PLANOS DE SAÚDE FILANTRÓPICAS: UMA ANÁLISE DOS DETERMINANTES NA PERSPECTIVA DA REGULAÇÃO DA AGÊNCIA NACIONAL DE SAÚDE SUPLEMENTAR (ANS) ${ }^{1}$}

\author{
Ewerton Alex Avelar ${ }^{2}$ \\ Terence Machado Boina \\ Antônio Artur de Souza \\ Hudson Fernandes Amaral
}

\begin{abstract}
RESUMO
Este artigo apresenta os resultados de uma pesquisa descritiva e quantitativa, que visou analisar os determinantes de endividamento em operadoras de planos de saúde (OPS) filantrópicas sob a perspectiva da regulação da Agência Nacional de Saúde Suplementar (ANS). A escolha dessa modalidade de operadora foi devido ao grande número de beneficiários atendidos e sua importância social. A amostra empregada consistiu nas OPS filantrópicas que apresentaram seus dados financeiros e operacionais ao longo do período de estudo (2010 a 2016) publicamente no site da ANS. Foram aplicadas as seguintes técnicas de análise de dados: análise de conteúdo, estatística descritiva e análise de regressão com dados em painel. Ao se analisar endividamento das OPS da modalidade Filantropia, observaram-se que variáveis clássicas empregadas como determinantes desse fenômeno em empresas foram consideradas significantes. Todas as variáveis relacionadas à regulação, que foram testadas, se mostraram significantes em pelo menos um modelo estimado. Diante do exposto, constatouse que as normas da ANS afetaram de diferentes formas às operadoras no que tange ao seu endividamento. Ademais, é importante destacar que a significância das variáveis (tanto as tradicionais de endividamento quanto as de regulação) dependeu do horizonte temporal abordado (curto ou longo prazo).
\end{abstract}

Palavras-chave: Determinantes do endividamento. Operadoras de planos de saúde. Agência Nacional de Saúde Suplementar. Operadoras filantrópicas.

\section{INTRODUÇÃO}

Pesquisas sobre estrutura de capital (endividamento) são consideradas relevantes na área de finanças (AN, 2012). Brito et al. (2007) ressaltam que a estrutura de capital se refere à forma como as organizações empregam capital próprio ou de terceiros para financiar seus

\footnotetext{
${ }^{1}$ Como citar este artigo: AVELAR, Ewerton Alex; BOINA, Terence Machado; SOUZA, Antônio Arthur de; AMARAL, Hudson Fernandes. Endividamento em operadoras de planos de saúde filantrópicas: uma análise dos determinantes na perspectiva da regulação da Agência Nacional de Saúde Suplementar (ANS). ForScience: revista científica do IFMG, Formiga, v. 7, n. 2, e00599, jul./dez. 2019. DOI:

10.29069/forscience.2019v7n2.e599.
}

\footnotetext{
${ }^{2}$ Autor para correspondência: Ewerton Alex Avelar, e-mail: ewertonaavelar@gmail.com
} 
ativos. O capital próprio usualmente se refere àquele fornecido pelos proprietários, enquanto o de terceiros normalmente se relaciona aos recursos obtidos por meio de dívidas.

Pode-se dizer que a literatura moderna em finanças corporativas foca principalmente em dois modelos para explicar o nível de endividamento das empresas: a trade-off theory (TOT) e a pecking order theroy (POT) (FAMA; FRENCH; 2005). Pohlmann e Iudícibus (2010) evidenciam que as duas teorias têm sido constantemente submetidas a testes, por meio de estudos teórico-empíricos, mas os resultados inconsistentes não permitem concluir sobre a capacidade explicativa de uma em relação à outra.

Brito et al. (2007) salientam que as teorias e os estudos sobre o tema enfatizam o emprego de variáveis que determinariam o nível de endividamento das organizações (variáveis determinantes). Dentre as principais variáveis determinantes do endividamento normalmente empregadas, podem ser citadas a tangibilidade dos ativos, o tamanho da empresa, a lucratividade/rentabilidade, o crescimento, a singularidade, os benefícios fiscais não provenientes de dívidas e o risco (TITMAN; WESSELS, 1988; RAJAN; ZINGALES, 1995; PEROBELLI; FAMA, 2002; FRANK; GOYAL, 2009; POHLMANN; IUDÍCIBUS, 2010; FORTE; BARROS; NAKAMURA, 2013; CAVALCANTI et al., 2016; CAVALCANTI et al., 2018).

Todavia, apesar da importância dada a decisões de financiamento e seu impacto no endividamento das organizações, há uma escassez de estudos que abordam esse fenômeno no que tange às operadoras de planos de saúde (OPS) brasileiras. A Agência Nacional de Saúde Suplementar (ANS, 2017) e Bragança (2017) afirmam que as OPS são organizações essenciais para o sistema de saúde brasileiro, atendendo dezenas de milhões de pessoas. Porém, muitas dessas organizações enfrentam problemas de gestão econômico-financeira, como ressalta a Associação Brasileira de Planos de Saúde (ABRAMGE, 2015). Salienta-se que as OPS são fortemente reguladas pela ANS, que influencia significativamente suas decisões financeiras (PINHEIRO et al., 2015).

Diante do exposto, a pesquisa cujos resultados são apresentados, neste artigo, visou responder ao seguinte problema de pesquisa: Variáveis relacionadas à regulação da ANS afetam o nível de endividamento das OPS filantrópicas? Nesse sentido, o objetivo geral do estudo foi analisar os determinantes de endividamento em OPS filantrópicas sob a perspectiva da regulação da ANS.

Dados da ANS (2018) indicam que mais de 47 milhões de beneficiários de planos de saúde utilizam o sistema de saúde suplementar, ou seja, quase $23,0 \%$ da população brasileira. 
Contudo, operadoras apresentam problemas de gestão (ABRAMGE, 2015). Ademais, além dos problemas já enfrentados pelas OPS no Brasil atualmente, Varella e Ceschin (2014) destacam que tal situação tende a piorar, caso essas organizações e os órgãos reguladores não mudem seu comportamento.

\section{REVISÃO DELITERATURA}

\subsection{Teorias sobre endividamento e variáveis determinantes}

Ross et al. (2015) destacam que as decisões de financiamento estão relacionadas basicamente à proporção de capital próprio e de terceiros que a organização terá em sua estrutura de capital. Salienta-se que a proporção entre o capital de terceiros e o patrimônio líquido de uma organização pode ser usada para representar o nível de endividamento da mesma. Fama e French (2005) afirmam que a literatura moderna em finanças corporativas, usualmente, enfatiza dois modelos concorrentes para explicar o nível de endividamento das empresas: a TOT e a POT. A TOT, segundo Lemmon e Zender (2010), prevê que as empresas tendem a escolher uma combinação de capital de terceiros e próprio que equilibre os custos e os benefícios da dívida. De acordo com esses autores, os benefícios da dívida e o controle dos fluxos de caixa livres incentivam as empresas ao endividamento, sem desconsiderar a probabilidade de falência e outros custos de agência (ou de transação).

Já a POT, conforme Frank e Goyal (2009), é baseada na assimetria informacional entre administradores e investidores. Assim, segundo esses autores, os administradores tendem a preferir empregar recursos gerados internamente, em função do menor risco de seleção adversa, em detrimento da emissão de títulos de propriedade que, sob a perspectiva dos investidores, apresenta maior risco. Desse modo, Brito et al. (2007) afirmam que, segundo a POT, as empresas em geral preferem financiar seus investimentos de acordo com a seguinte hierarquia: (1) lucros; (2) dívidas; e (3) novas ações.

Brito et al. (2007) ressaltam que as teorias sobre endividamento foram desenvolvidas em conjunto com a realização de uma série de pesquisas empíricas, nacionais e internacionais, que visaram identificar as principais variáveis que determinariam o nível de endividamento das empresas, tais como: tangibilidade dos ativos, tamanho da empresa, lucratividade/rentabilidade, crescimento, singularidade, benefícios fiscais não provenientes de dívidas e risco. 
A tangibilidade dos ativos afeta o nível de endividamento das empresas, pois, geralmente, os ativos tangíveis podem ser oferecidos como garantia em empréstimos (POHLMANN; IUDÍCIBUS, 2010). Já o tamanho (porte) pode influenciar o nível de endividamento das empresas, uma vez que as grandes empresas tendem a possuir negócios mais diversificados, ter melhor reputação junto a credores e menores níveis de assimetria informacional (FRANK; GOYAL, 2009).

Por sua vez, a lucratividade/rentabilidade é uma variável essencial no estudo sobre o endividamento das empresas (FAMA; FRENCH, 2005). Contudo, há discordâncias na interpretação do efeito dessa variável sobre o nível de endividamento de uma empresa, de acordo com a teoria empregada para se analisar o fenômeno: segundo a POT, empresas com maiores indicadores de lucratividade/rentabilidade tendem a empregar menos recursos de terceiros; porém, o inverso é esperado pela TOT (POHLMANN; IUDÍCIBUS, 2010).

Para Fama e French (2005), a variável crescimento também é muito relevante na explicação do nível de endividamento de uma empresa. Porém, Forte, Barros e Nakamura (2013) também destacam contradições teóricas sobre o efeito de tal variável. De acordo com esses autores, empresas em fase de crescimento tendem a se endividar mais sob a perspectiva da POT. Por outro lado, sob a perspectiva da TOT, espera-se que empresas com elevadas taxas de crescimento tenham alto custo de falência (reduzindo o endividamento), pois parte substancial do seu valor está ligada às expectativas futuras de lucro e não a ativos que podem ser liquidados (BRITO et al., 2007).

Espera-se, ainda, que empresas com maior nível de singularidade (ou seja, algo que as torna únicas) sejam mais conservadoras, de modo a evitar altos níveis de endividamento (PEROBELLI; FAMA, 2002). No caso dos benefícios fiscais não provenientes de dívidas, há uma relação negativa, pois quanto maior a dedução de depreciações e amortizações, menores resultados estariam disponíveis para as deduções provenientes da dívida (DEANGELO; MASULIS, 1980). Por fim, a variável risco é negativamente relacionada ao nível de endividamento, pois as perdas esperadas pela maior probabilidade de falência são representadas por taxas de juros de capital de terceiros substancialmente mais altas e os custos de falência esperados aumentam quando a empresa apresenta altos níveis de alavancagem (FORTE; BARROS; NAKAMURA, 2013). No Quadro 1, são apresentadas as formas de cálculo das variáveis geralmente empregadas em modelos econométricos que explicam o endividamento de empresas. 

na perspectiva da regulação da Agência Nacional de Saúde Suplementar (ANS)

\begin{tabular}{|c|c|c|c|}
\hline Variável & Sigla & Cálculo & Referências \\
\hline Endividamento geral & EGA & $(\mathrm{PC}+\mathrm{PNC}) \div \mathrm{AT}$ & Brito et al. (2007), Ceretta et al. (2009). \\
\hline $\begin{array}{l}\text { Endividamento de } \\
\text { curto prazo }\end{array}$ & $\mathrm{ECP}$ & $\mathrm{PC} \div \mathrm{AT}$ & Brito et al. (2007). \\
\hline $\begin{array}{l}\text { Endividamento de } \\
\text { longo prazo }\end{array}$ & ELP & $\mathrm{PNC} \div \mathrm{AT}$ & Brito et al. (2007). \\
\hline Tangibilidade & TANG & $\mathrm{AF} \div \mathrm{AT}$ & Rajan e Zingales (1995) e Ceretta et al. (2009). \\
\hline Tamanho & TAM & $\ln (\mathrm{AT})$ & Fama e French (2002) e Lemmon e Zender (2010). \\
\hline $\begin{array}{l}\text { Lucratividade/ } \\
\text { rentabilidade }\end{array}$ & LUC & $\mathrm{EBIT} \div \mathrm{RL}$ & $\begin{array}{l}\text { Titman e Wessels (1988), Perobelli e Fama (2002) e } \\
\text { Pohlmann e Iudícibus (2010). }\end{array}$ \\
\hline Crescimento & CRES & $\begin{array}{l}\left(\mathrm{AT}_{\mathrm{t}+1}-\mathrm{AT}_{\mathrm{t}}\right) \div \\
\mathrm{AT}_{\mathrm{t}}\end{array}$ & $\begin{array}{l}\text { Titman e Wessels (1988), Perobelli e Fama (2002) e } \\
\text { Fama e French (2005). }\end{array}$ \\
\hline $\begin{array}{l}\text { Escudo fiscal não } \\
\text { proveniente de } \\
\text { dívidas }\end{array}$ & EFNPD & $\begin{array}{l}(\mathrm{DEP}+\mathrm{AMOR}) \div \\
\mathrm{AT}\end{array}$ & Ceretta et al. (2009) \\
\hline Singularidade & SING & $\mathrm{INT} \div \mathrm{AT}$ & Titman e Wessels (1988) e Perobelli e Fama (2002). \\
\hline Risco & RIS & $\begin{array}{l}\mathrm{AC}-(\mathrm{EST}+\mathrm{DA}) \\
\div \mathrm{PC}\end{array}$ & Ceretta et al. (2009). \\
\hline
\end{tabular}

Quadro 1 - Operacionalização de variáveis empregadas em modelos de endividamento

Fonte: Elaborado pelos autores.

Notas: AC - Ativo circulante; PC - Passivo circulante; PNC - Passivo não circulante; AT - Ativo total; RL Receita líquida; EBIT - Earnings before interest and taxes; EBT - Earnings before taxes; ln - Logaritmo natural; AF - Ativo fixo; DEP - Depreciação; AMOR - Amortização; INT - Intangível; EST - Estoques; DA Despesas antecipadas

Por sua vez, a Figura 1 apresenta os sinais esperados da relação entre essas variáveis e o nível de endividamento das organizações, de acordo com as diferentes teorias: POT e TOT. Com base na referida figura, observa-se que as principais diferenças entre a previsão das teorias se refere às variáveis lucratividade e crescimento, como já discutido anteriormente com base em Fama e French (2005), Pohlmann e Iudícibus (2010) e Forte, Barros e Nakamura (2013) Ademais, salienta-se que a POT não apresenta uma previsão de relação entre algumas variáveis citadas e o fenômeno do endividamento. 


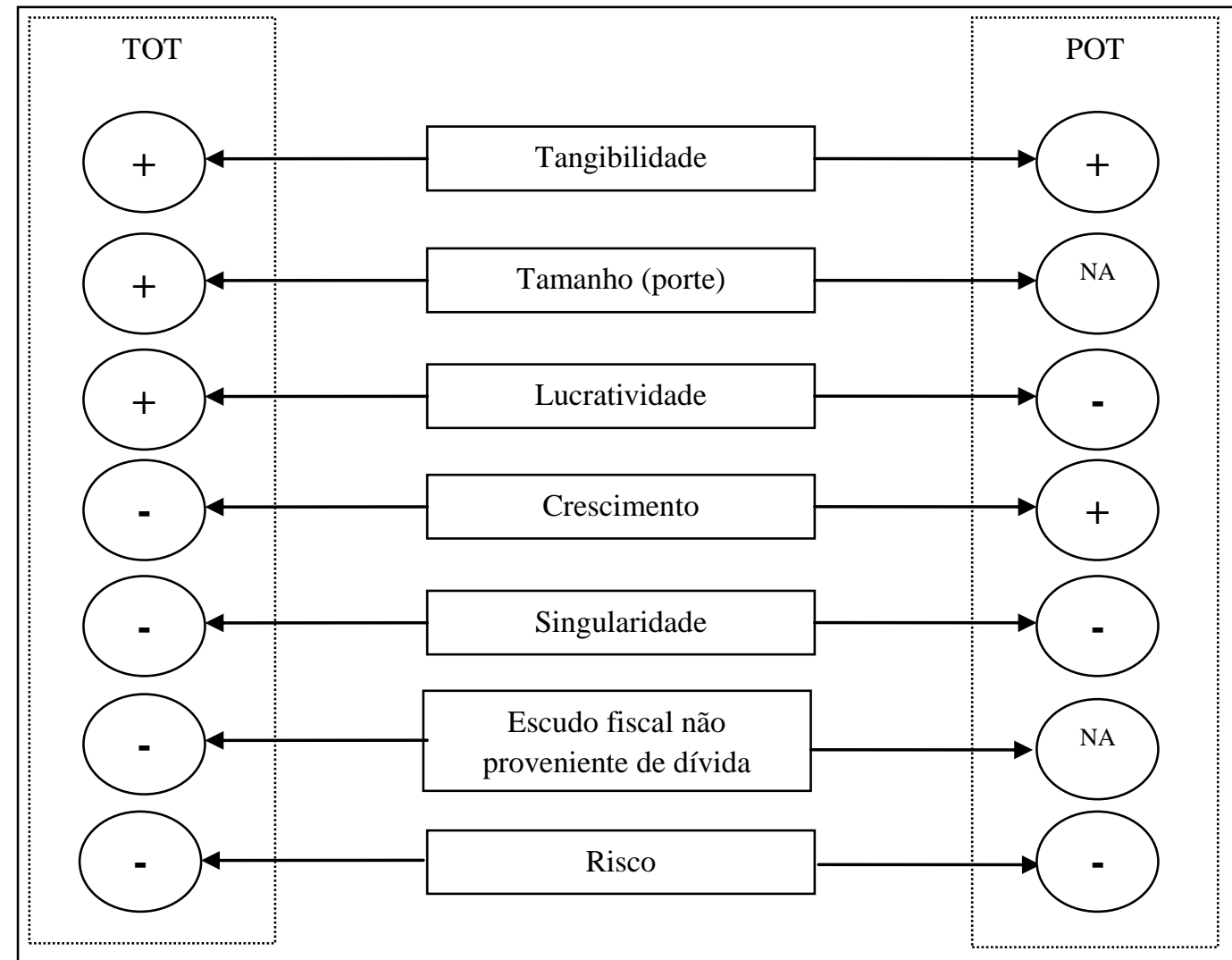

Figura 1 - Relação entre as variáveis determinantes da estrutura de capital, considerando as teorias TOT e POT Fonte: Elaborado com base em Frank e Goyal (2009), Brito et al. (2007), Pohlmann e Iudícibus (2010), Forte, Barros e Nakamura (2013) e Correa et al. (2013).

Nota: NA equivale a "Não se aplica".

É importante salientar que, ao se operacionalizar a variável endividamento na pesquisa apresentada neste artigo, optou-se por considerar o que Rajan e Zingales (1995) denominam de "definição ampliada de endividamento", ou seja, o total de passivos (tanto onerosos quanto não onerosos) dividido pelo total de ativos. Essa opção se justifica devido aos dados empregados para análise, dos quais a maioria dos passivos era não onerosa. Ademais, autores empregaram a definição mais ampla de endividamento ao analisarem esse fenômeno especificamente no Brasil, como Brito et al. (2007) e Ceretta et al. (2009), facilitando a comparabilidade dos achados.

Além disso, Welch (2011) e Cavalcanti et al. (2016) ressaltam a importância de se considerar as variáveis determinantes do nível de endividamento, de acordo com aspecto temporal, pois há variáveis que seriam mais relevantes para explicar o nível de endividamento de curto prazo e outras para explicar o fenômeno no longo prazo. Por fim, Lemmon e Zender (2010) e Pinheiro et al. (2015) salientam que a regulação de determinados setores da economia também influencia o nível de endividamento das organizações. Assim, tem-se que a 
regulação da ANS sobre as OPS tende a ter impacto significativo nos resultados econômicos, dessas organizações tal como evidencia Leal (2014).

\subsection{Regulação da ANS sobre as operadoras}

Pode-se definir as OPS como organizações que fornecem um abrangente conjunto de serviços de saúde a seus beneficiários, que usualmente pagam um valor fixo mensal. Apesar de existir há décadas no Brasil, a operação de planos de saúde só passou a ser efetivamente regulada por intermédio da Lei $n^{\circ}$ 9.656, de 03/06/1998, que disciplinou o funcionamento desses planos e a atuação das organizações que poderiam ser definidas como operadoras (BRASIL, 1998). Nesse contexto, criou-se a ANS, por meio da Medida Provisória no 2012-2, de 30/12/1999, convertida na Lei $n^{\circ}$ 9.961, de 28/01/2000. Veloso e Malik (2010) ressaltam que a regulação da ANS levou a limitações no aumento dos prêmios, à padronização de coberturas de atendimento e a uma menor diferenciação entre as operadoras, ao mesmo tempo em que houve uma grande ampliação nos direitos dos usuários.

As OPS brasileiras são classificadas em diferentes modalidades pela Resolução de Diretoria Colegiada (RDC) da ANS: administradora, cooperativa médica, cooperativa odontológica, autogestão, medicina de grupo, odontologia de grupo ou filantropia (ANS, 2000). Na pesquisa apresentada neste trabalho, foram estudadas as operadoras da modalidade Filantropia. Segundo a ANS (2000), são filantrópicas:

[...] as entidades sem fins lucrativos que operam Planos Privados de Assistência à Saúde e tenham obtido o certificado de entidade beneficente de assistência social emitido pelo Ministério competente, dentro do prazo de validade, bem como da declaração de utilidade pública federal junto ao Ministério da Justiça ou declaração de utilidade pública estadual ou municipal junto aos Órgãos dos Governos Estaduais e Municipais, na forma da regulamentação normativa específica vigente (ANS, 2000, online).

A Tabela 1 apresenta o número de beneficiários de OPS da modalidade Filantropia, assim como o número dessas operadoras no período de 2000 a 2016. Observa-se uma queda, em termos absolutos, tanto do número de beneficiários quanto do número de operadoras ativas. Todavia, há um aumento médio no número de beneficiários por operadora. Salienta-se que a queda observada no número de operadoras (apesar do aumento médio no número de beneficiários) é discutida em estudos como os de Silva e Loebel (2016) e Bragança (2017). A regulação da ANS pode ter influenciado esse fenômeno e gerar problemas para os beneficiários das OPS, considerando a possível formação de um oligopólio no setor. 
Tabela 1 - beneficiários de OPS da modalidade Filantropia e de operadoras filantrópicas no período de 2000 a 2016

\begin{tabular}{c|cc}
\hline Período & Número de beneficiários (em milhões) & Número de operadoras ativas \\
\hline 2010 & 1,5 & 93 \\
2011 & 1,5 & 96 \\
2012 & 1,5 & 88 \\
2013 & 1,5 & 78 \\
2014 & 1,2 & 76 \\
2015 & 1,1 & 58 \\
2016 & 1,0 & \\
\hline
\end{tabular}

Fonte: ANS (2018).

Diante do exposto, foram desenvolvidas hipóteses sobre a regulação imposta pela ANS sobre as OPS estudadas e que tem potencial de influenciar as decisões de financiamento dos gestores das operadoras de saúde. Primeiramente, tem-se que, conforme a Ação de Inconstitucionalidade $\mathrm{n}^{\mathrm{o}}$ 1.931/2003, os planos de saúde contratados antes da regulação da ANS (conhecidos como "planos antigos") não se submetem às normas dessa Agência Reguladora, valendo o contrato entre as partes (OPS e beneficiários) (SUPREMO TRIBUNAL FEDERAL, 2003). Assim, desenvolveu-se a Hipótese 1.

A proporção de "planos antigos" em suas carteiras tem relação significante Hipótese 1 (positiva segundo a TOT e negativa conforme a POT) com o endividamento das OPS filantrópicas.

O estabelecimento de preços de planos de saúde individuais, decisão essencial para as OPS, deve ser realizado segundo as normas da ANS. No caso dos idosos (que mais utilizam), ressalta-se que a ANS exige que o reajuste de planos de saúde fique restrito a um valor fixo em relação à primeira faixa etária (necessariamente a mais barata), o que fez com que as OPS tenham receitas reduzidas e custos alavancados (KUDLAWICZ; STEINER NETO; FREGA, 2015). Dessa forma, desenvolveu-se a Hipótese 2.

A idade média dos beneficiários (em planos individuais) tem relação Hipótese 2 significante (positiva segundo a POT e negativa conforme a TOT) com o endividamento das OPS filantrópicas.

O reajuste de planos de saúde individuais é distinto dos coletivos (ligados a empresas e outras organizações). Enquanto os primeiros só podem ser reajustados com autorização da ANS, os planos coletivos, com algumas limitações, são reajustados com base na negociação entre as partes (VARELLA; CESCHIN, 2014). Assim, espera-se que as OPS tenham 
preferências pelos planos coletivos para garantir melhor seus interesses, tal como evidenciado por Leal (2014). Com base nisso, desenvolveu-se a Hipótese 3.

A proporção de beneficiários de planos coletivos em suas carteiras tem relação

Hipótese 3 significante (positiva segundo a TOT e negativa conforme a POT) com o endividamento das OPS filantrópicas.

A ANS considera o porte da OPS em suas normas, devido à sua capilaridade, estabelecendo tratamento diferenciado para pequenas e médias OPS. A ANS visa reduzir as despesas administrativas das operadoras de menor porte, especialmente em relação às exigências econômico-financeiras (BALDASSARE, 2014). Com base no exposto, desenvolveu-se a Hipótese 4.

\section{Hipótese 4}

O porte da OPS tem relação significante (positiva segundo a TOT e negativa conforme a POT) com o endividamento das OPS filantrópicas.

De acordo com a região de atuação da OPS, a ANS exige diferentes níveis de recursos próprios mínimos (Patrimônio Líquido Ajustado - PMA) e a constituição de provisões técnicas, de acordo com a Resolução Normativa (RN) 209/2009 (ANS, 2009). O PMA é o requisito mínimo de patrimônio que uma operadora deve possuir para operar em uma dada área (seis áreas no total), independentemente de seu porte; enquanto as provisões técnicas representam o risco esperado, mensurado com base em critérios do negócio e que exigem garantias reais (PINHEIRO et al., 2015). Assim, desenvolveu-se a Hipótese 5. Salienta-se que, nesse caso, não é possível prever a direção da relação (positiva ou negativa) por se tratarem de algumas dummies que representam diferentes regiões conforme a RN 209/2009.

\section{Hipótese 5}

A região de atuação da OPS tem relação significante com o endividamento das OPS filantrópicas.

Pode-se dizer o principal instrumento adotado no programa de avaliação das OPS no Brasil é o Índice de Desempenho da Saúde Suplementar (IDSS), usado para mensurar o desempenho das operadoras. O IDSS avalia, simultaneamente, uma série de aspectos ligados às diferentes dimensões das operadoras (operacionais, sanitárias, satisfação dos beneficiários etc.) (ANS, 2018). Para obter melhores resultados em todos os índices que compõem o IDSS, espera-se que uma série de atividades (e dispêndios) extras sejam realizadas pelas operadoras. Nesse contexto, desenvolveu-se a Hipótese 6. 
O desempenho obtido por uma OPS no IDSS tem relação significante

Hipótese 6 (positiva segundo a POT e negativa conforme a TOT) com o endividamento das OPS filantrópicas.

Outro aspecto importante na regulação da ANS sobre as operadoras se refere ao regime de direção fiscal de uma OPS por parte da ANS. Segundo Bragança (2017), tal regime demanda a presença de um Diretor Fiscal, designado pela ANS, que requisita remuneração paga pela OPS. Dessa forma, espera-se que uma operadora que já tenha passado pelo regime de direção fiscal tenha suas decisões financeiras mais alinhadas à regulação da ANS. Desse modo, foi proposta a Hipótese 7.

Hipótese 7

O fato de a OPS ter passado pelo regime de direção fiscal tem relação significante com o endividamento das OPS filantrópicas.

Conforme Veloso e Malik (2010) houve alterações na relação das OPS após a criação da ANS. Contudo, anteriormente, não existiam limites específicos na atuação das operadoras. Assim, desenvolveu-se a Hipótese 8.

O fato de a OPS ter sido criada e registrada após a criação da ANS tem relação Hipótese 8 significante (positiva segundo a TOT e negativa conforme a POT) com o endividamento das OPS filantrópicas.

Por fim, a razão de dependência expressa "a relação percentual entre o número de menores de 15 anos, somados aos maiores de 60 anos sobre os beneficiários entre 15 e 59 anos" (ANS, 2016, p.4). Nesse caso, espera-se que o endividamento das operadoras seja influenciado de acordo com a proporção desses beneficiários. Desse modo, desenvolveu-se a Hipótese 9.

\section{Hipótese 9}

A razão de dependência das OPS tem relação significante (negativa segundo a TOT e positiva conforme a POT) com o endividamento das OPS filantrópicas.

Ressalta-se que, para testar as hipóteses supracitadas em modelos econométricos, foi empregada uma série de variáveis relacionadas a cada uma das hipóteses propostas (Quadro 2). Incluiu-se, ainda, uma variável de controle relacionada ao fato de a OPS possuir ou não um hospital próprio (variável obtida com base em dados solicitados pelos pesquisadores à ANS se valendo da Lei de Acesso à Informação (LAI). A propriedade de um hospital tende a aumentar a alavancagem operacional das organizações (ativo fixo relevante), o que pode 
influenciar significativamente seu nível de endividamento. Por se tratar de um ativo de realização no longo prazo, espera-se que haja um maior nível de recursos captados para seu financiamento com liquidação no mesmo período.

\begin{tabular}{|c|c|c|c|c|}
\hline Hip & Variável & Sigla & Cálculo & Referências \\
\hline 1 & $\begin{array}{l}\text { Proporção de planos } \\
\text { antigos }\end{array}$ & ANT & $\mathrm{BPA} \div \mathrm{BTO}$ & ANS (2018) \\
\hline 2 & $\begin{array}{l}\text { Idade média dos } \\
\text { beneficiários }\end{array}$ & IDA & $\frac{\text { ¿Idade média dos beneficiários }}{\text { Número de beneficiários }}$ & ANS (2016) \\
\hline 3 & $\begin{array}{l}\% \text { de beneficiários de } \\
\text { planos coletivos }\end{array}$ & $\mathrm{COL}$ & $\mathrm{PCOL} \div(\mathrm{PCOL}+\mathrm{PIND})$ & $\begin{array}{l}\text { Adaptado de ANS } \\
(2016)\end{array}$ \\
\hline 4 & Porte da OPS & TAM & $\operatorname{Ln}($ Ativo) & $\begin{array}{l}\text { Baldassare (2014) e } \\
\text { ANS (2011) }\end{array}$ \\
\hline 5 & $\begin{array}{l}\text { Região de atuação das } \\
\text { OPS }\end{array}$ & CDR & $\begin{array}{l}\text { Se a operadora atua em uma dada } \\
\text { região (1 a 5), coloca-se o valor } 1 ; \text { se } \\
\text { não, } 0 \text {. (Variável dummy) }\end{array}$ & ANS (2009) \\
\hline 6 & IDSS & IDSS & Valor do índice calculado pela ANS. & ANS (2016) \\
\hline 7 & Direção Fiscal & $\mathrm{DF}$ & $\begin{array}{c}\text { Se a operadora já havia passado pelo } \\
\text { regime de gestão fiscal da ANS, } 1 ; \text { Se } \\
\text { não, } 0 . \text { (Variável dummy) }\end{array}$ & $\begin{array}{l}\text { Lei de Acesso à } \\
\text { Informação (LAI) }\end{array}$ \\
\hline 8 & Registro ANS & RANS & $\begin{array}{l}\text { Se a operadora foi registrada antes da } \\
\text { criação da ANS, } 0 \text {; Se não, } 1 . \\
\text { (Variável dummy) }\end{array}$ & LAI \\
\hline 9 & Razão de dependência & DEP & M15M60 $\div$ OBE & ANS (2016) \\
\hline NA & Hospital & HOS & $\begin{array}{c}\text { Se a OPS possui hospital próprio, } 1 ; \mathrm{Se} \\
\text { não, 0. (Variável dummy) }\end{array}$ & LAI \\
\hline
\end{tabular}

Quadro 2 - Operacionalização de variáveis relacionadas à regulação

Fonte: Elaborado pelos autores.

Notas: BPA - Beneficiários de planos antigos; BTO - Total de beneficiários; M15M60 - Beneficiários menores de 15 anos e maiores de 60; OBE - Beneficiários maiores de 15 anos e menores de 60; PCOL - Beneficiários de planos coletivos; PIND - Beneficiários de planos individuais; NA - Não se aplica.

\section{MATERIAL E MÉTODOS}

A pesquisa apresentada, neste artigo, pode ser classificada essencialmente como descritiva e quantitativa. A amostra empregada consistiu nas OPS filantrópicas que apresentaram seus dados financeiros e operacionais ao longo do período de estudo (2010 a 2016) publicamente no site da ANS. A escolha dessa modalidade de operadora se deu devido ao grande número de beneficiários atendidos, sua queda significativa nos últimos anos e sua importância social, tal como destacado na seção 2.2 deste trabalho. A Tabela 2 apresenta o número de OPS que compôs a amostra por ano.

Tabela 2 - Número de OPS que compôs a amostra no período de realização da pesquisa

\begin{tabular}{c|ccccccc}
\hline Modalidade & $\mathbf{2 0 1 0}$ & $\mathbf{2 0 1 1}$ & $\mathbf{2 0 1 2}$ & $\mathbf{2 0 1 3}$ & $\mathbf{2 0 1 4}$ & $\mathbf{2 0 1 5}$ & $\mathbf{2 0 1 6}$ \\
\hline Filantropia & 51 & 58 & 38 & 38 & 31 & 30 & 27 \\
\hline
\end{tabular}

Fonte: Dados da pesquisa. 
É importante destacar que foram coletados dados a partir de 2010, devido à significativa convergência das normas brasileiras de Contabilidade às normas internacionais a partir do referido ano e que teve impactos relevantes nas informações financeiras reportadas pelas organizações (GELBECK et al., 2018). Já no caso do ano de 2016, este foi o ano mais recente ao quais os pesquisadores tiveram acesso durante o período da pesquisa.

Para o desenvolvimento do estudo, foram empregados dados secundários. Todos os dados das contas foram padronizados em um plano de contas padrão que atendesse aos objetivos dos pesquisadores. Posteriormente, os dados foram utilizados para se calcular as variáveis para análise. Em análises nas quais os outliers corromperam os parâmetros pressupostos pelas técnicas usadas, as referidas observações foram excluídas, considerando três desvios padrões para mais ou menos em relação à média, tal como desenvolvido por Baldassare (2014).

Foram aplicadas as seguintes técnicas de análise de dados: análise de conteúdo, estatística descritiva e análise de regressão com dados em painel. A análise de conteúdo foi empregada na legislação e normas relacionadas à saúde suplementar, de forma a identificar variáveis regulatórias que pudessem influenciar o endividamento das organizações estudadas. A estatística descritiva, por sua vez, foi empregada para se analisar especialmente informações sobre medidas de tendência central, assim como a dispersão e a correlação entre as variáveis analisadas das OPS filantrópicas.

No que se relaciona à análise de regressão com dados em painel, Gujarati et al. (2011) apresentam três abordagens comumente empregadas: (i) Modelo pooled ordinary least square (POLS); (ii) Modelo de Efeitos Fixos (MEF); e (iii) Modelo de Efeitos Aleatórios (MEA). Esses autores ressaltam que é possível que se avalie o modelo mais adequado a partir de testes específicos: (a) teste de Chow - POLS versus MEF; (b) teste de Breusch-Godfrey - POLS versus MEA; e (c) teste de Hausman - MEF versus MEA.

No estudo realizado, a análise de regressão com dados em painel foi empregada para o desenvolvimento de modelos que explicassem a influência de variáveis relacionadas à regulação da ANS sobre o endividamento das organizações analisadas. Nesse caso, foram tratadas como variáveis dependentes as seguintes: EGA, ECP e ELP. Foram empregadas como variáveis independentes aquelas relacionadas à regulação (Quadro 2) e as empregadas em estudos clássicos e empíricos como determinantes do endividamento de empresas (Quadro 1). Os modelos estimados são apresentados nas equações 1,2 e 3 . Em todos os modelos, $\beta_{0}$ 
representa o intercepto; $\varepsilon$ representa o termo de erro e os subscritos $i$ e $t$ especificam, respectivamente, as observações quanto às organizações e aos anos abrangidos pelo estudo.

$$
\begin{aligned}
& E G A_{\text {it }}=\beta_{0}+\beta_{1} \times \text { TANG }_{\text {it }}+\beta_{2} \times \text { TAM }_{\text {it }}+\beta_{3} \times L U C_{\text {it }}+\beta_{4} \times \text { CRES it }_{\text {it }}+\beta_{5} \times S I N G_{\text {it }}+\beta_{6} \times E F N P D_{\text {it }}+\beta_{7} \\
& \times R I S_{\text {it }}+\beta_{g} \times A N T_{\text {it }}+\beta_{9} \times D E P_{\text {it }}+\beta_{10} \times I D A_{\text {it }}+\beta_{11} \times C O L_{\text {it }}+\beta_{12} \times C D R 1_{\text {it }}+\beta_{19} \\
& \times C D R 2_{\text {it }}+\beta_{14} \times C D R 3_{\text {it }}+\beta_{15} \times C D R 4_{i t}+\beta_{16} \times C D R 5_{i t}+\beta_{17} \times I D S S_{i t}+\beta_{18} \times \text { RANS }_{\text {it }} \\
& +\beta_{19} \times D F_{i t}+\beta_{20} \times \operatorname{HOSP}_{\text {it }}+\varepsilon_{\text {it }} \\
& E C P_{\text {it }}=\beta_{0}+\beta_{1} \times \text { TANG }_{\text {it }}+\beta_{2} \times \text { TAM }_{\text {it }}+\beta_{2} \times L U C_{\text {it }}+\beta_{4} \times \text { CRES it }_{\text {it }}+\beta_{5} \times S I N G_{\text {it }}+\beta_{6} \times \text { EFNPD }_{\text {it }}+\beta_{7} \\
& \times R I S_{\text {it }}+\beta_{9} \times A N T_{\text {it }}+\beta_{9} \times D E P_{\text {it }}+\beta_{10} \times I D A_{\text {it }}+\beta_{11} \times C O L_{\text {it }}+\beta_{12} \times C D R 1_{\text {it }}+\beta_{13} \\
& \times C D R 2_{\text {it }}+\beta_{14} \times C D R 3_{\text {it }}+\beta_{15} \times C D R 4_{\text {it }}+\beta_{16} \times C D R 5_{\text {it }}+\beta_{17} \times I D S S_{\text {it }}+\beta_{18} \text { l RANS }_{\text {it }} \\
& +\beta_{19} \times D F_{i t}+\beta_{20} \times H O S P_{i t}+\varepsilon_{i t} \\
& E L P_{\text {it }}=\beta_{0}+\beta_{1} \times \text { TANG }_{\text {it }}+\beta_{2} \times \text { TAM }_{\text {it }}+\beta_{2} \times L U C_{\text {it }}+\beta_{4} \times \text { CRES }_{\text {it }}+\beta_{5} \times S I N G_{\text {it }}+\beta_{6} \times E F N P D_{\text {it }}+\beta_{7} \\
& \times R I S_{\text {it }}+\beta_{9} \times A N T_{\text {it }}+\beta_{9} \times D E P_{\text {it }}+\beta_{10} \times I D A_{\text {it }}+\beta_{11} \times C O L_{\text {it }}+\beta_{12} \times C D R 1_{\text {it }}+\beta_{13} \\
& \times C D R 2_{i t}+\beta_{14} \times C D R 3_{i t}+\beta_{15} \times C D R 4_{i t}+\beta_{16} \times C D R 5_{i t}+\beta_{17} \times I D S S_{i t}+\beta_{18} \times \text { RANS }_{\text {it }} \\
& +\beta_{19} \times D F_{i t}+\beta_{20} \times H O S P_{i t}+\varepsilon_{i t}
\end{aligned}
$$

Para avaliar a qualidade geral de ajustamento dos modelos estimados, empregaram-se o $\mathrm{R}^{2}$ ajustado e o Teste F, tal como destacado por Gujarati et al. (2011). Para análise dos resíduos, foram calculados os testes de Anderson-Darling, Breush-Pagan e Durbin-Watson, para avaliar, respectivamente, a normalidade, a homoscedasticidade e a ausência de autocorrelação, conforme recomendado por Gujarati et al. (2011) e Fávero (2015). Para evitar problemas com multicolinearidade, foi realizada uma análise de correlação das variáveis independentes em cada modelo e excluídas aquelas que apresentavam coeficientes estatisticamente significantes. Ressalta-se que, em casos de heteroscedasticidade e presença de autocorrelação dos resíduos, empregou-se o modelo de Arellano (1993 citado por Arellano, 2003) para corrigir tais disfunções.

\section{RESULTADOS E DISCUSSÃO}

Apresenta-se, nesta seção, a análise do efeito das variáveis regulatórias sobre o endividamento das OPS filantrópicas. Na Tabela 3, apresentam-se estatísticas descritivas das variáveis dependentes dos modelos estimados. Ao se analisar esta tabela, observou-se que, em média, as OPS classificadas na modalidade Filantropia empregaram mais recursos de terceiros que próprios para financiar seus ativos. A maior proporção desses recursos de terceiros, em média, vencia no curto prazo. 
Tabela 3 - Estatísticas descritivas das variáveis dependentes dos modelos estimados para as OPS filantrópicas

\begin{tabular}{c|cccccc}
\hline Variável & Mínimo & $\mathbf{1}^{\mathbf{0}}$ Quartil & Mediana & Média & $\mathbf{3}^{\circ}$ Quartil & Máximo \\
\hline EGA & 0,01 & 0,41 & 0,56 & 0,57 & 0,75 & 1,00 \\
ECP & 0,01 & 0,27 & 0,37 & 0,37 & 0,48 & 0,77 \\
ELP & - & 0,09 & 0,17 & 0,20 & 0,30 & 0,61 \\
\hline
\end{tabular}

Fonte: Dados da pesquisa.

Já na Tabela 4, apresentam-se os resultados dos modelos estimados para o endividamento dessas operadoras. Salienta-se que, após a realização dos testes de Chow, Breusch-Godfrey e Hausman, concluiu-se que o modelo MEF era o mais adequado para o desenvolvimento das regressões. Observa-se que algumas variáveis foram excluídas devido a problemas de multicolinearidade, quais sejam: RANS e HOSP. A análise dos resultados da Tabela 4 indica que, no modelo EGA, as variáveis tradicionalmente relacionadas ao endividamento consideradas significantes foram RIS e SING. Os coeficientes estimados para ambas as variáveis apresentaram sinais negativos, indo ao encontro do esperado na literatura de acordo com Perobelli e Fama (2002) e Forte, Barros e Nakamura (2013).

Tabela 4 - Estatísticas dos modelos de endividamento para as operadoras filantrópicas

\begin{tabular}{|c|c|c|c|c|c|c|}
\hline Variável Y & \multicolumn{2}{|l|}{ EGA } & \multicolumn{2}{|l|}{ ECP } & \multicolumn{2}{|l|}{ ELP } \\
\hline Equação & \multicolumn{2}{|l|}{1} & \multicolumn{2}{|l|}{2} & \multicolumn{2}{|l|}{3} \\
\hline Modelo & \multicolumn{2}{|l|}{ MEF } & \multicolumn{2}{|l|}{ MEF } & \multicolumn{2}{|l|}{ MEF } \\
\hline Variável & Coeficiente & P-valor & Coeficiente & $\begin{array}{l}\text { P- } \\
\text { valor }\end{array}$ & Coeficiente & P-valor \\
\hline RIS & $-0,08$ & $\mathbf{0 , 0 2}$ & $-0,17$ & 0,02 & 0,14 & $\mathbf{0 , 0 2}$ \\
\hline LUC & $-0,51$ & 0,37 & $-0,56$ & 0,24 & $-0,12$ & 0,83 \\
\hline TANG & 0,23 & 0,53 & $-0,57$ & 0,07 & 1,40 & $\mathbf{0 , 0 0}$ \\
\hline SING & $-6,05$ & $\mathbf{0 , 0 0}$ & $-0,92$ & 1,39 & $-3,27$ & 0,24 \\
\hline TAM & $\mathbf{0 , 0 8}$ & $\mathbf{0 , 0 0}$ & & & $\mathbf{0 , 1 1}$ & $\mathbf{0 , 0 0}$ \\
\hline CRES & 0,10 & 0,52 & & & 0,00 & 0,99 \\
\hline EFNPD & $-0,07$ & 0,89 & $-0,29$ & 0,41 & $-0,44$ & 0,54 \\
\hline DF & 0,12 & $\mathbf{0 , 0 0}$ & $\mathbf{0 , 0 1}$ & $\mathbf{0 , 0 3}$ & 0,09 & 0,14 \\
\hline CDR3 & 0,11 & 0,11 & & & 0,14 & $\mathbf{0 , 0 1}$ \\
\hline CDR4 & 0,27 & $\mathbf{0 , 0 2}$ & $\mathbf{0 , 0 1}$ & $\mathbf{0 , 0 3}$ & 0,27 & $\mathbf{0 , 0 0}$ \\
\hline CDR5 & & & $\mathbf{0 , 0 1}$ & $\mathbf{0 , 0 1}$ & 0,03 & 0,27 \\
\hline IDA & & & 0,00 & $\mathbf{0 , 0 0}$ & $-0,01$ & $\mathbf{0 , 0 3}$ \\
\hline IDSS & 0,71 & $\mathbf{0 , 0 0}$ & 0,02 & 0,08 & $\mathbf{0 , 5 8}$ & $\mathbf{0 , 0 3}$ \\
\hline COL & $-0,17$ & 0,28 & $-0,09$ & 0,05 & 0,03 & 0,83 \\
\hline ANT & 0,32 & 0,38 & $-0,06$ & 0,09 & 0,96 & $\mathbf{0 , 0 1}$ \\
\hline \multirow[t]{6}{*}{ DEP } & $-2,04$ & $\mathbf{0 , 0 0}$ & 0,11 & 0,26 & $-2,65$ & $\mathbf{0 , 0 0}$ \\
\hline & $\mathrm{R}^{2}$ ajustado & $58,30 \%$ & $\mathrm{R}^{2}$ ajustado & $80,50 \%$ & $\mathrm{R}^{2}$ ajustado & $63,80 \%$ \\
\hline & Teste F & $5,16^{* *}$ & Teste F & $14,39^{* *}$ & Teste F & $5,17^{* *}$ \\
\hline & Anderson-Darling & 0,3 & Anderson-Darling & 0,41 & Anderson-Darling & 0,32 \\
\hline & Breusch-Pagan & 21,15 & Breusch-Pagan & 12,57 & Breusch-Pagan & 17,54 \\
\hline & Durbin-Watson & $1,38^{*}$ & Durbin-Watson & 1,75 & Durbin-Watson & 2,00 \\
\hline
\end{tabular}

Fonte: Dados da pesquisa.

Notas: ${ }^{*}$ Significante a $5,0 \% ;{ }^{* *}$ Significante a $1,0 \%$.

No que se refere às variáveis relacionadas à regulação, foram consideradas significantes TAM, CDR4, IDSS, DF e DEP. Assim, as operadoras que atuaram na Região 4 
e/ou de maior porte tenderam a apresentar maiores níveis de endividamento. Salienta-se que a Região 4 engloba os municípios de Belo Horizonte, São Paulo, Rio de Janeiro e Brasília ou Curitiba ou Porto Alegre (ANS, 2009). O maior nível de endividamento observado das operadoras dessa região pode estar relacionado à maior demanda de planos nessa região (grandes municípios do país), o que exigiria a busca de capital de terceiros da operadora para atender à demanda existente. Já a constatação no caso da variável TAM corrobora o exposto por Frank e Goyal (2009), que afirmam que organizações maiores tendem a ter melhores condições de obtenção de recursos junto a terceiros (devido à diversificação e à reputação).

Observou-se também um maior nível de endividamento das operadoras que já passaram pelo regime de direção fiscal da ANS e/ou obtiveram maiores valores de IDSS. Por outro lado, aquelas que apresentaram maior indicador de dependência tenderam a apresentar menores níveis de endividamento geral. Esta situação pode estar atrelada ao fato de que maiores níveis de dependência tendem a demandar maiores recursos para cobrir sinistros em relação às demais. Assim, a busca por financiamento externo pode ficar mais intricada devido ao maior risco envolvido.

Por sua vez, ao se analisar as estatísticas do modelo ECP para as operadoras filantrópicas, verificou-se que a única variável tradicionalmente relacionada ao endividamento considerada significante foi RIS (com coeficiente negativo). Dentre as variáveis relacionadas à regulação, foram consideradas significantes: DF, CDR4, CDR5, IDA, COL. No caso desta última variável, o coeficiente estimado foi negativo em contraposição às demais, cujos coeficientes foram positivos.

Por fim, as estatísticas do modelo ELP indicaram que as variáveis tradicionalmente relacionadas ao endividamento consideradas significantes foram RIS e TANG. No caso do endividamento de longo prazo, o coeficiente da variável TANG apresentou sinal esperado, de acordo com a literatura, ao contrário da variável RIS. No que se refere às variáveis ligadas à regulação, foram consideradas significantes TAM, CDR3, CDR4, IDA, IDSS, ANT e DEP. No caso da variável TAM, verificou-se que as operadoras de maior porte tenderam a apresentar um maior nível de endividamento no longo prazo, novamente ratificando o exposto por Frank e Goyal (2009). Ademais, constatou-se que operadoras que atuaram nas regiões 3 e/ou 4 tenderam a apresentar um maior nível de endividamento de longo prazo. Salienta-se que a Região 3 congrega as operadoras que atuaram em um único estado, desde que não seja o de São Paulo (ANS, 2009). 
Já operadoras que apresentaram um maior indicador de dependência e/ou uma maior idade média entre os seus beneficiários tenderam a apresentar menor nível de endividamento no longo prazo. Uma possível explicação para a situação observada para a variável DEP no longo prazo é semelhante a do endividamento geral. Já no caso da variável IDA, pressupondose que pessoas mais velhas tendem a apresentar uma maior demanda de serviços, mas com a contraprestação fixada pela ANS, nas operadoras, seus gestores podem ter maiores dificuldades em obter recursos de longo prazo, devido ao maior risco associado às mesmas. Por outro lado, operadoras com maiores níveis de IDSS e/ou maior proporção de planos antigos em sua carteira tenderam a apresentar maiores níveis de ELP. A Figura 2 apresenta um resumo das variáveis de regulação da ANS testadas e os sinais dos coeficientes significantes estimados.

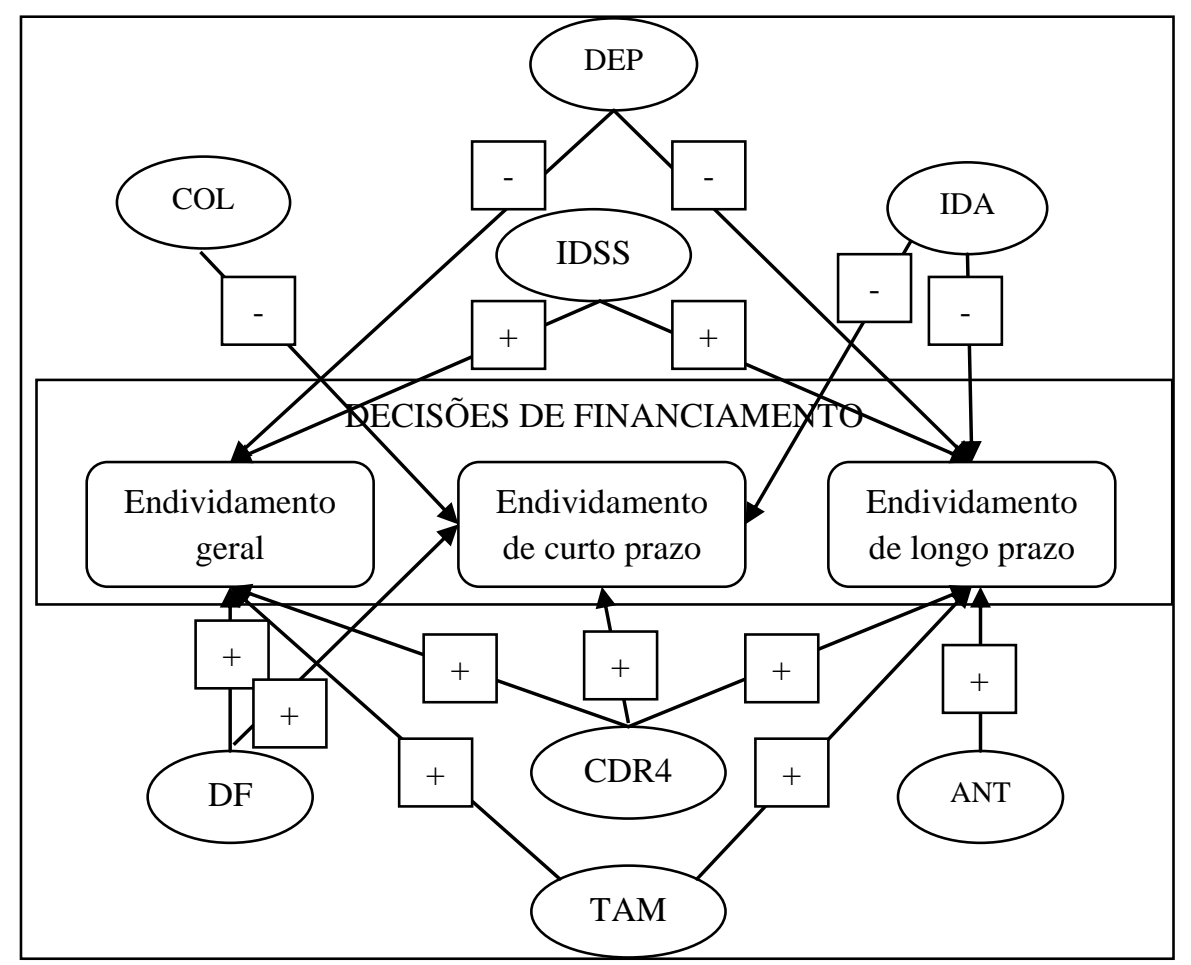

Figura 2: Relações significantes entre as variáveis de regulação e o endividamento de OPS filantrópicas Fonte: Elaborado pelos autores.

Já no Quadro 3, destacam-se as conclusões sobre cada uma das hipóteses desenvolvidas na seção 2.2. Ressalta-se que todas as variáveis ligadas à regulação da ANS testadas se mostraram significantes em, pelo menos, um dos modelos estimados. 


\begin{tabular}{|c|c|c|c|c|c|}
\hline \multirow{2}{*}{ Relações } & \multirow{2}{*}{ Variável } & \multicolumn{2}{|c|}{ Sinal esperado } & \multirow{2}{*}{$\begin{array}{c}\text { Sinal } \\
\text { encontrado }\end{array}$} & \multirow{2}{*}{ Hipóteses } \\
\hline & & TOT & POT & & \\
\hline \multirow{7}{*}{$\begin{array}{l}\text { Hipóteses sobre } \\
\text { as Teorias de } \\
\text { endividamento } \\
\text { e suas } \\
\text { determinantes }\end{array}$} & Tangibilidade (TANG) & + & + & + & Aceita \\
\hline & Tamanho (TAM) & + & NA & + & Aceita \\
\hline & Lucratividade/Rentabilidade (LUC) & + & - & NS & Rejeitada \\
\hline & Crescimento (CRES) & - & + & + & Aceita \\
\hline & $\begin{array}{l}\text { Escudo fiscal não proveniente de dívidas } \\
\text { (EFNPD) }\end{array}$ & - & NA & NS & Rejeitada \\
\hline & Singularidade (SING) & - & - & - & Aceita \\
\hline & Risco (RIS) & - & - & $-1+$ & Aceita \\
\hline Hipóteses & \begin{tabular}{|l} 
Variável \\
\end{tabular} & \multicolumn{2}{|c|}{ Sinal esperado } & & \\
\hline \multirow{10}{*}{$\begin{array}{c}\text { Hipóteses sobre } \\
\text { a regulação } \\
\text { imposta pela } \\
\text { ANS sobre o } \\
\text { endividamento } \\
\text { das OPS }\end{array}$} & H1 - Proporção de planos antigos (ANT) & + & - & + & Aceita \\
\hline & H2 - Idade média dos beneficiários (IDA) & - & + & $+1-$ & Aceita \\
\hline & $\begin{array}{l}\text { H3 - Proporção de beneficiários de planos } \\
\text { coletivos (COL) }\end{array}$ & + & - & - & Aceita \\
\hline & H4 - Porte da OPS (TAM) & + & - & + & Aceita \\
\hline & H5 - Região de atuação das OPS (CDR) & NA & NA & + & Aceita \\
\hline & H6 - IDSS & - & + & + & Aceita \\
\hline & H7 - Direção Fiscal (DF) & ND & ND & + & Aceita \\
\hline & H8 - Registro ANS (RANS) & + & - & NT & - \\
\hline & H9 - Razão de dependência (DEP) & - & + & - & Aceita \\
\hline & Hospital (HOS) & ND & ND & NT & - \\
\hline
\end{tabular}

Quadro 3 - Resumo das conclusões referentes às hipóteses desenvolvidas sobre os efeitos da regulação sobre o endividamento das operadoras da modalidade Filantropia

Fonte: Elaborado pelos autores.

Notas: NA - Não se aplica; ND - Não determinada previamente; NS - Não significante; NT - Não testada.

\section{CONSIDERAÇÕES FINAIS}

Ao se analisar endividamento das OPS da modalidade filantropia, observaram-se variáveis clássicas empregadas como determinantes desse fenômeno em empresas (abordadas na seção 2.1) foram consideradas significantes. Contudo, é importante destacar que determinadas variáveis clássicas apresentaram um coeficiente estimado com sinal divergente do esperado com base na literatura. Tal situação pode estar relacionada ao emprego de um conceito mais amplo de endividamento, na concepção de Rajan e Zingales (1995).

Todas as variáveis relacionadas à regulação, que foram testadas, se mostraram significantes em, pelo menos, um modelo estimado. Diante do exposto, constata-se que as normas da ANS afetaram de diferentes formas às operadoras no que tange ao seu endividamento, tal como sugerido por Pinheiro et al. (2015). Ademais, é importante destacar que a significância das variáveis (tanto as tradicionais de endividamento quanto as de regulação) dependeu do horizonte temporal abordado (curto ou longo prazo). Tal constatação realça a importância de se considerar o endividamento em diversos horizontes temporais, como afirmam Welch (2011) e Cavalcanti et al. (2016).

Dentre as contribuições desta pesquisa para o conhecimento na área estudada, realçase a importância da regulação no nível de endividamento das OPS estudadas. Este estudo 
deixou clara a relação entre normas regulatórias e o desempenho das operadoras filantrópicas. Assim, evidenciou-se a importância de se considerar a regulação no desempenho dessas organizações e, consequentemente, na quantidade e na qualidade do serviço prestado à sociedade. O estudo também demonstrou a validade de variáveis tradicionais em modelos para explicar endividamento em organizações de saúde. Outra contribuição da pesquisa foi a proposição de variáveis regulatórias para auxiliar na explicação do endividamento nas operadoras. Essas variáveis ainda não haviam sido testadas em modelos semelhantes no Brasil e demonstraram sua capacidade de refletir a influência da regulação sobre o endividamento das organizações estudadas.

Todavia, apesar das contribuições supracitadas, é relevante destacar as limitações do estudo desenvolvido. Primeiramente, ressalta-se a amostra limitada. Ademais, apesar dos esforços no desenvolvimento das variáveis de regulação, elas são limitadas diante dos dados disponíveis para o seu cálculo. Trata-se de uma limitação inerente a estudos como este, tal como ressaltam Fama e French (2005). Esses autores afirmam que as métricas empregadas necessitam de aprimoramento. Outro ponto a se destacar é que, para alguns modelos econométricos, não foi possível empregar todos os dados disponíveis para análise, restringindo-se àqueles que compartilhavam os parâmetros necessários para atender aos pressupostos dos modelos.

Diante das contribuições e das limitações citadas, pesquisas futuras poderiam testar as variáveis de regulação propostas no estudo ora apresentado em outros contextos, sejam de novas amostras ou diferentes horizontes temporais. Além disso, tais estudos poderiam propor novas variáveis a serem exploradas no que tange à regulação das OPS filantrópicas. Ademais, a amostra poderia ser ampliada com organizações de saúde suplementar categorizadas pela ANS (2000) não discutidas neste artigo. Poder-se-ia, ainda, desenvolver pesquisas, sob a percepção dos reguladores e dos gestores, sobre os efeitos da regulação nas organizações estudadas. Tais pesquisas poderiam ter um enfoque mais qualitativo, a partir de técnicas de coleta de dados, como entrevistas estruturadas ou semiestruturadas e grupos focais.

Agradecimento: Coordenação de Aperfeiçoamento de Pessoal de Nível Superior (CAPES) e Fundação de Apoio à Pesquisa de Minas Gerais (FAPEMIG). 


\title{
INDEBTEDNESS DETERMINANTS IN PHILANTHROPIC PRIVATE HEALTHCARE PROVIDERS: AN ANALYSIS BASED ON THE SUPPLEMENTARY HEALTH AGENCY (ANS) REGULATION
}

\begin{abstract}
This paper presents the results of a study aimed at analyzing the indebtedness determinants of philanthropic Brazilian private healthcare providers (OPS) under the Supplementary Health Agency (ANS) regulation. This modality of OPS was chosen due to the high number of users and its social relevance. The study was a descriptive, quantitative and explanatory one. The employed sample consisted of healthcare OPS whose 2010-2016 data are publicly available on the ANS website. Data analysis followed these techniques: contend analysis, descriptive statistics and data panel regression. We verified that some traditional variables employed in corporative environment were statistically significant. We also observed the significance of many variables related to regulation. This indicates that such variables influence OPS indebtedness. Moreover, it is important to stress that the variables significance level varies according to the time lag (short or long-term). We can cited important contributions of this study: (a) enhancing the important of regulation on the selected OPS; (b) demonstrating the validity of traditional variables for explaining the indebtedness models in these organizations; and (c) purposing regulatory variables in order to explain the indebtedness in philanthropic OPS.
\end{abstract}

Keywords: Indebtedness determinants. Private healthcare providers (OPS). Supplementary Health Agency (ANS). Philanthropic OPS.

\section{REFERÊNCIAS}

ASSOCIAÇÃO BRASILEIRA DE PLANOS DE SAÚDE - ABRAMGE. Custo cresce mais que receita, dizem planos. 2015. Disponível em: http://blog.abramge.com.br/mundocorporativo/economia-mercado/custo-cresce-mais-que-receita-dizem-planos/. Acesso em: 11 jan. 2018.

AGÊNCIA NACIONAL DE SAÚDE SUPLEMENTAR - ANS. Resolução de Diretoria Colegiada - RDC n' 39, de 27 de outubro de 2000. 2000. Disponível em:

http://www.ans.gov.br/component/legislacao/?view=legislacao\&task=TextoLei\&format=raw \&id=Mzgw. Acesso em: $06 \mathrm{dez} .2015$.

AGÊNCIA NACIONAL DE SAÚDE SUPLEMENTAR - ANS. RN n⿳2 209, de 22 de

dezembro de 2009. Dispõe sobre os critérios de manutenção de Recursos Próprios Mínimos e constituição de Provisões Técnicas a serem observados pelas operadoras de planos privados de assistência à saúde. 2009. Disponível em:

http://www.ans.gov.br/component/legislacao/?view=legislacao\&task=TextoLei

\&format=raw\&id=MTU3MQ. Acesso em: 16 fev. 2018.

AGÊNCIA NACIONAL DE SAÚDE SUPLEMENTAR - ANS. Dados e Indicadores do

Setor. 2016. Disponível em: http://www.ans.gov.br/perfil-do-setor/dados-e-indicadores-dosetor. Acesso em: 06 jan. 2016. 
AGÊNCIA NACIONAL DE SAÚDE SUPLEMENTAR - ANS. Caderno de Informação da Saúde Suplementar: Beneficiários, Operadoras e Planos - Junho 2017. 2017. Disponível em: http://www.ans.gov.br/images/stories/Materiais_para_pesquisa/Perfil_setor/Caderno_informa cao_saude_suplementar/caderno_informacao_junho_2017.pdf. Acesso em: 16 fev. 2018.

AGÊNCIA NACIONAL DE SAÚDE SUPLEMENTAR - ANS. Programa de Qualificação de Operadoras. 2018. Disponível em: http://www.ans.gov.br/planos-de-saude-eoperadoras/informacoes-e-avaliacoes-de-operadoras/qualificacao-ans. Acesso em: 15 jan. 2018.

AN, Zhioyong. Taxation and capital structure: empirical evidence from a quasi-experiment in China. Journal of Corporate Finance, Amsterdan, v. 18, p. 683-689, 2012.

ARELLANO, Manuel. Panel data econometrics: advanced texts in econometrics. Oxford: Oxford University Press, 2003.

BALDASSARE, Renato Madrid. Análise do desempenho econômico-financeiro de operadoras de planos de saúde no mercado de saúde suplementar brasileiro. 2014. $97 \mathrm{f}$. Dissertação (Mestrado em Administração de Empresas) - Fundação Getúlio Vargas, São Paulo, 2014.

BRAGANÇA, Ciro Gustavo Liquidação de operadoras de planos de assistência à saúde no Brasil. 2017. 115 f. Dissertação (Mestrado em Controladoria e Contabilidade) Universidade Federal de Minas Gerais, Belo Horizonte, 2017.

BRASIL. Lei no 9.961, de 28 de janeiro de 2000. Cria a Agência Nacional de Saúde Suplementar - ANS e dá outras providências. Brasília, 2000. Disponível em: http://www.planalto.gov.br/ccivil_03/leis/19961.htm. Acesso em: 1 maio 2015.

BRASIL. Lei $\mathbf{n}^{\mathbf{0}}$ 9656, de 3 de junho de 1998. 1998. Dispõe sobre os planos e seguros privados de assistência à saúde. Disponível em: http://www.planalto.gov.br/ccivil_03/Leis/L9656.htm. Acesso em: 30 nov. 2015.

BRITO, Giovani Antonio Silva; CORRAR, Luiz J.; BATISTELLA, Flávio Donizete. Fatores determinantes da estrutura de capital das maiores empresas que atuam no Brasil. Revista Contabilidade \& Finanças, São Paulo, v. 18, n. 43, p. 9-19, 2007.

CAVALCANTI, Joyce Mariella Medeiros; CASTRO, Sarah Laine; AVELAR, Ewerton Alex; LAZO, Renato Paz; MÓL, Anderson Luis Rezende. Financial debt stratification and capital structure determinants of companies listed in the BM\&FBOVESPA. Revista de Gestão, Finanças e Contabilidade, Salvador, v. 6, n. 3, p. 125-142, 2016.

CAVALCANTI, Joyce Mariella Medeiros; CASTRO, Sarah Laine; AVELAR, Ewerton Alex; LAZO, Renato Paz; MÓL, Anderson Luis Rezende. Relevância das características dos CEO’s na estrutura de capital de empresas listadas no IBRX-100 da BM \& FBOVESPA. Revista Pretexto, Belo Horizonte, v. 19, n. 1, p. 25-42, 2018.

CERETTA, Paulo Sérgio; VIEIRA, Kelmara Mendes; FONSECA, Juliara Lopes da; TRINDADE, Larissa de Lima. Determinantes da estrutura de capital: uma análise de dados 
em painel de empresas pertencentes ao Ibovespa no período de 1995 a 2007. Revista de Gestão USP, São Paulo, v. 16, n. 4, p. 29-43, 2009.

DEANGELO, Harry; MASULIS, Ronald. Optimal capital structure under corporate and personal taxation. Journal of Financial Economics, Lausanne, v. 8, n. 1, p. 3-27, 1980.

FAMA, Eugene; FRENCH, Kenneth. Financing decisions: who issues stock? Journal of Financial Economics, Lausanne, v. 76, n. 3, p. 549-582, 2005.

FÁVERO, Luiz Paulo. Análise de dados: Modelos de regressão com Excel®, Stata® e SPSS®. Rio de Janeiro: Elsevier, 2015.

FORTE, Denis; BARROS, Lucas Ayres; NAKAMURA, Wilson Toshiro. Determinants of the capital structure of small and medium sized Brazilian enterprises. Brazilian Administration Review, Maringá, v. 10, n. 3, p. 347-369, 2013.

FRANK, Murray Z.; GOYAL, Vidhan K. Capital structure decisions: which factors are reliably important? Financial Management, Tampa, v. 38, n. 1, p. 1-37, 2009.

GELBECK, Ernesto Rubens; SANTOS, Ariovaldo dos; LUDÍCIBUS, Sérgio de; MARTINS, Eliseu. Manual de contabilidade societária. 3. ed. São Paulo: Atlas, 2018.

GUJARATI, Damodar N.; PORTER, Dawn C.; DURANTE, Denise; ROSEMBERG, Mônica; ROSA, Maria Lúcia G. L.; ARAÚJO JÚNIOR, Claudio Shikida de; SALVATO, Ari Francisco Márcio Antônio. Econometria básica. 5. ed. Porto Alegre: AMGH, 2011.

KUDLAWICZ, Claudineia; STEINER NETO, Pedro José; FREGA, José Roberto. Homogeneidade e rentabilidade: o caso das operadoras de planos de saúde. Revista de Informação Contábil, Recife, v. 9, n. 1, p. 50-67, 2015.

LEAL, Rodrigo Mendes. O mercado de saúde suplementar no Brasil: regulação e resultados econômicos dos planos privados de saúde. In: JORNADA DE ESTUDOS DE REGULAÇÃO, 8. Rio de Janeiro, Anais [...], Rio de Janeiro, 2014.

LEMMON, Michael L.; ZENDER, Jaime. F. Debt Capacity and Tests of Capital Structure Theories. Journal of Financial and Quantitative Analysis, Seatle, v. 45, n. 5, p. 1161-1187, 2010 .

PEROBELLI, Fernanda Finotti Cordeiro; FAMA, Rubens. Determinantes da estrutura de capital: aplicação a empresas de capital aberto brasileiras. Revista de Administração, São Paulo, v. 37, n. 3, p.33-46, 2002.

PINHEIRO, Isabel Cristina Barbosa; PELEIAS, Ivam Ricardo; SILVA, Aldy Fernandes da; MARTINS, Eliseu. Efeitos da regulação econômico-financeira nas estratégias de financiamento das operadoras de planos de saúde. Revista Universo Contábil, Blumenau, v. 11, n. 2, p. 108-127, 2015.

POHLMANN, Marcelo Coletto; IUDICIBUS, Sérgio de. Relação entre a tributação do lucro e a estrutura de capital das grandes empresas no Brasil. Revista Contabilidade \& Finanças, São Paulo, v. 21, n. 53, p. 1-25, 2010. 
RAJAN, Raghuram G.; ZINGALES, Luigi. What do we know about capital structure? some evidence from international data. The Journal of Finance, New York, v. 50, n. 5, p. 14211460, 1995.

ROSS, Stephen A.; WESTERFIELD, Randolph W.; JAFFE, Jeffrey; LAMB, Roberto. Administração financeira. 10. ed. São Paulo: AMGH, 2015.

SILVA, Victor Vieira; LOEBEL, Eduardo. Análise do desempenho econômico-financeiro de operadoras de planos privados de saúde do setor brasileiro de saúde. Revista de

Administração Hospitalar e Inovação em Saúde, Belo Horizonte, v. 13, n. 3, p. 1-21, 2016.

SUPREMO TRIBUNAL FEDERAL. Ação direta de inconstitucionalidade (Med. liminar) 1931. 2003. Disponível em:

http://www.stf.jus.br/portal/peticaoInicial/verPeticaoInicial.asp?base=ADIN\&s1=1931\&proce sso=1931. Acesso em: 10 fev. 2017.

TITMAN, Sheridan; WESSELS, Roberto. The determinants of capital structure choice. The Journal of Finance, New York, v. 43, n. 1, p. 1-19, 1988.

VARELLA, Drauzio; CESCHIN, Mauricio. A saúde dos planos de saúde: os desafios da assistência privada no Brasil. São Paulo: Paralela, 2014.

VELOSO, Germany Gonçalves; MALIK, Ana Maria. Análise do desempenho econômicofinanceiro de empresas de saúde. RAE-eletrônica, São Paulo, v. 9, n. 1, p. 1-22, 2010.

WELCH, Ivo. Two Common Problems in Capital Structure Research: The Financial-Debt-toAsset Ratio and Issuing Activity Versus Leverage Changes. International Review of Finance, Hong Kong, v. 11, n. 1, p. 1-17, 2011.

\section{DADOS DOS AUTORES}

\section{Ewerton Alex Avelar}

E-mail: ewertonalexavelar@gmail.com

Currículo Lattes: http://lattes.cnpq.br/6758338709153591

Doutor em Administração pela Universidade Federal de Minas Gerais (UFMG), mestre em Administração pela Universidade Federal de Lavras (UFLA), especialista em Educação pela Universidade Federal Fluminense (UFF) e graduado em Ciências Contábeis pela UFMG. Atualmente é Professor Adjunto do Departamento de Ciências Contábeis da UFMG. Atua principalmente nos seguintes temas: Controle Gerencial, Gestão de Custos, Pesquisa em Administração e em Contabilidade, Sistemas de Informações, Redes Sociais, Educação a Distância e Finanças.

\section{Terence Machado Boina}

E-mail: tmboina@gmail.com

Currículo Lattes: http://lattes.cnpq.br/1469445616579643 
Mestre em Ciências Contábeis pela Universidade Federal do Rio de Janeiro (UFRJ) e graduado em Ciências Contábeis pela UFMG. Atualmente é Analista Administrativo da Agência Nacional do Cinema. Pesquisa principalmente os seguintes temas: Contabilidade Financeira, Contabilidade Gerencial e Pesquisa em Contabilidade.

\section{Antônio Artur de Souza}

E-mail: antonioarturdesouza@gmail.com

Currículo Lattes: http://lattes.cnpq.br/0597505816212353

Pós-doutor em Finanças pela Universidade de Grenoble (França), doutor em Management Science pela Universidade de Lancaster (Inglaterra), mestre em Engenharia de Produção e bacharel em Ciências Contábeis pela Universidade Federal de Santa Catarina (UFSC). Atualmente é professor Associado IV da UFMG.

\section{Hudson Fernandes Amaral}

E-mail: hfamaral.cepead@gmail.com

Currículo Lattes: http://lattes.cnpq.br/3459819354945294

Doutorado em "Sciences de Gestion - Université Pierre Mendès France - ESA - Grenoble II França“, mestrado em Diplôme d'Etudes Approfondies en Sciences de Gestion - Université Des Sciences Sociales de Toulouse I - França, especialização em Finanças pela Fundação João Pinheiro e graduação em Administração pela UFMG. Professor Titular do Centro Universitário Unihorizontes. Membro do Comitê de Assessoramento do Programa Básico de Administração - $\mathrm{AE}$ do $\mathrm{CNPq}$ (2018-2020). Professor Titular aposentado do CEPEAD/CAD/FACE da Universidade Federal de Minas Gerais - UFMG, onde lecionou de 1994 a 2018. 